\title{
Bioremediation of PCP by Trichoderma and Cunninghamella Strains Isolated from Sawdust
}

\author{
Ngieng Ngui Sing ${ }^{1}$, Azham Zulkharnain ${ }^{1}$, Hairul Azman Roslan ${ }^{1}$, Zani Assim $^{2}$ and Ahmad \\ Husaini $^{1 *}$ \\ ${ }^{I}$ Department of Molecular Biology; ${ }^{2}$ Department of Chemistry; Faculty of Resource Science and Technology; \\ Universiti Malaysia Sarawak; Kota Samarahan Sarawak - Malaysia
}

\begin{abstract}
Four fungal isolates, SD12, SD14, SD19 and SD20 isolated from the aged sawdust grew on agar plates supplemented with PCP up to a concentration of $100 \mathrm{mg} \mathrm{L}^{-1}$. At high PCP concentration, isolate SD12 showed the highest radial growth rate of $10 \mathrm{~mm} \mathrm{day}^{-1}$, followed by SD14 and SD19 both with $4.5 \mathrm{~mm}$ day ${ }^{-1}$ and SD20 with $4.2 \mathrm{~mm}$ day ${ }^{-1}$. Ultrastructural study on the effect of PCP on the PCP tolerant fungi using scanning electron microscope showed that high concentration of PCP caused the collapse of both fungal hyphae and spores. Among the four PCP tolerant fungi examined, isolate SD12 showed the least structural damage at high PCP concentration of $100 \mathrm{mg} \mathrm{L}^{-1}$. This fungal isolate was further characterized and identified as Cunninghamella sp. UMAS SD12. Preliminary PCP biodegradation trial performed in liquid minimal medium supplemented with $20 \mathrm{mg} \mathrm{L}^{-1}$ of PCP using Cunninghamella sp. UMAS SD12 showed that the degradation up to $51.7 \%$ of PCP in 15 days under static growth condition.
\end{abstract}

Key words: Pentachlorophenol, Fungi, Cunninghamella sp., Scanning Electron Microscopy, PCP degradation

\section{INTRODUCTION}

Pentachlorophenol (PCP) is a widespread, persistent environmental contaminant that has been, and in some developing countries still is one of the extensively used fungicides and pesticides, especially in wood preservation (McAllister et al. 1996; Ge et al. 2007). PCP has been classified as a priority pollutant by the U.S. Environmental Protection Agency (Keither and Teilard 1979) and has been banned for all usage in certain countries such as India, New Zealand, Sweden and Germany (Ge et al. 2007). Despite being banned and restricted in certain countries due to its toxic effect on health and environment, PCP still remains an important pesticide from a toxicological perspective (Proudfoot 2003). PCP is very toxic. Short term exposure to high level of PCP can cause damage to the central nervous system, while long term exposure, especially for workers in the wood preserving industries can cause serious damage to the liver and kidney (Fisher 1991). PCP is also a possible carcinogen to human (IARC 1999). Dermal exposure to PCP by sawmill workers has been associated with the cases of nonHodgkin's lymphoma, multiple myeloma, kidney cancer and also with a number of physical and neuropsychological health effects in former sawmill workers that persisted long after PCP exposure had ceased (Demers et al. 2006; McLean et al. 2009).

The highest reported usage of PCP is in the wood preserving and treatment industry, where PCP has been widely used to protect the utility poles, cross arms, construction lumber, fence post and many other wood related products from fungal rots, decay and staining by sapstain fungi (Tuomela et al. 1999). The use of PCP in dip treatment of

*Author for correspondence: haahmad@ frst.unimas.my 
freshly sawn lumber, which usually occurs in open-air basins, however, has caused pollution of soil and water in the area (McAllister et al. 1996). Soil samples obtained from the sawmills contained as high as $4500 \mathrm{mg}$ of chlorophenols per kg of dry soil (Persson et al. 2007). Even soil samples obtained from an abandoned sawmill area were also reported to be contaminated with chlorophenols that leached deep into the soil (Kitunen and Salkinoja-Salonen 1990).

Fungi are a promising source for the remediation of PCP contaminated site. Many fungi such as Phanerochaete chrysosporium, Trametes versicolor and Pleurotus species degrade PCP (Mileski et al. 1988; Tuomela et al. 1999; Ryu et al. 2000). These basidiomycetes are also known as the white-rot fungi as they are able to decompose lignin in lignocellulosic materials to cause white rotting of wood (Novotny et al. 1999). Due to the non-specific and non-stereoselective free radical mechanism in the decomposition of lignin by these fungi, they can, therefore, be utilized for the degradation of a wide variety of organopollutants, including PCP (Mileski et al. 1988).

Sawdust is the main by-product of wood processing in sawmills that is produced from cutting the wood with a saw (Akpomie et al. 2013). In sawmills, sawdust is generally regarded as a waste that is often heaped or burnt (Lennox et al. 2010). The high recalcitrance lignocellulose content of sawdust has prompted for the isolation of fungi from sawdust such as Aspergillus niger, Trichoderma sp. and Penicillium sp. for its degradation (Nwodo-Chinedu et al. 2005; Lennox et al. 2010). Despite the ability of these fungi to degrade the sawdust, fungi isolated from sawdust, however, have rarely been examined for their ability to degrade PCP, which has been widely applied as a wood preservative in sawmill.

This work aimed in isolation and characterization of fungal isolates from sawdust for PCP degradation and to study the effect of PCP on the morphological structure of the isolated PCPtolerant fungi using scanning electron microscopy (SEM).

\section{MATERIALS AND METHODS}

\section{Collection of samples}

Wet and decomposed sawdust samples that were long exposed to the environment were collected from a sawmill factory in Kota Samarahan, Sarawak.

\section{Isolation of fungi}

Fungal isolation were performed using spread plate, pour plate and also by the soil plate method (Giraud et al. 2001). For the soil plate method, 1.0 $\mathrm{g}$ of the sample was taken into Petri dishes before sterile agar medium was poured over. Each samples for each isolation method were done in triplicate on Malt Extract Agar (MEA, pH5.6) and incubated at $28^{\circ} \mathrm{C}$. Fungal isolates were distinguished by their colony morphology and subcultured periodically for further analysis.

\section{Fungal growth sensitivity towards pentachlorophenol}

The sensitivity of the isolated fungi towards PCP was determined by measuring the rate of mycelial growth of each fungus grown on yeast malt peptone glucose (YMPG) (pH 5.5) agar plates, supplemented with various concentrations of PCP, ranging from 0 to $20 \mathrm{mg} \mathrm{L}^{-1}$ (Lamar et al. 1990). The agar plates were inoculated with $5 \mathrm{~mm}^{2}$ plug cut out of an actively growing fungal mycelium and incubated at $28^{\circ} \mathrm{C}$. Three replicates were prepared for each fungal isolate at each PCP concentration. Mycelial growth was measured daily for 14 days and only the maximum mycelia extension rate observed for these isolates were selected. Based on the preliminary results obtained, fungal isolates that showed high radial growth rate (in the presence of PCP) and high tolerance (in term of the least growth reduction in the presence of PCP) towards PCP at $20 \mathrm{mg} \mathrm{L}^{-1}$ were further subjected to a higher PCP concentration of 50 and $100 \mathrm{mg} \mathrm{L}^{-1}$.

\section{Scanning electron microscopy (SEM) analysis}

Four fungal isolates capable of growing on agar plates supplemented with $100 \mathrm{mg} \mathrm{L}^{-1}$ of PCP were selected for ultrastructural examination under SEM. Small pieces of agar blocks $\left(5 \times 5 \mathrm{~mm}^{2}\right)(\mathrm{pH}$ 5.5) containing 14 days old fungal mycelium and spores were cut out from PCP supplemented agar plates $\left(0 \mathrm{mg} \mathrm{L}^{-1}\right.$ and $\left.100 \mathrm{mg} \mathrm{L}^{-1}\right)$ and fixed overnight using 3\% glutaraldehyde in $0.1 \mathrm{M}$ potassium phosphate buffer $(\mathrm{pH}$ 7.2) in a refrigerator. The agar blocks were then washed three times with $0.1 \mathrm{M}$ potassium phosphate buffer ( $\mathrm{pH}$ 7.2) before dehydrating with a series of aqueous acetone ranging from $30,50,70,80,85$, 90, 95 and $100 \%(\mathrm{v} / \mathrm{v})$ for $15 \mathrm{~min}$. Fixation, 
washing and dehydration were all performed in 1.5 $\mathrm{mL}$ microcentrifuge tubes. Using acetone as the intermediate fluid, the dehydrated specimens were critical point dried (Bal-Tec CPD 030) with liquid carbon dioxide. The pieces of agar blocks with mycelium and fungal spores facing up were then placed onto aluminium stub using carbon tape and sputter coated with palladium (Jeol: JFC-1600 Auto Fine Coater) before the fungal hyphae and spores were examined under SEM (Jeol: JSM6390LA Analytical SEM) (Bianchi et al. 1997; Manoch et al. 2008).

\section{Fungal characterization and identification}

Fungal isolates that tolerated up $100 \mathrm{mg} \mathrm{L}^{-1}$ of PCP were characterized morphologically and molecularly. The morphological appearances of the selected fungal isolates grown on Malt Extract Agar (MEA) plates were characterized by visual observation and by micro-morphological techniques. As for molecular identification, fungal DNA was extracted according to the method of Cubero et al. (1999) and amplified using a universal primer pair ITS1 (5'TCCGTAGGTGAACCTGCGG-3') and ITS4 (5'TCCTCCGCTTATTGATATGC-3') (White et al. 1990) under the following conditions: initial denaturation at $95^{\circ} \mathrm{C}$ for $5 \mathrm{~min}, 30$ cycles of denaturation at $95^{\circ} \mathrm{C}$ for $1 \mathrm{~min}$, annealing at $55^{\circ} \mathrm{C}$ for $1 \mathrm{~min}$, extension at $72^{\circ} \mathrm{C}$ for $1 \mathrm{~min}$ and final extension at $72^{\circ} \mathrm{C}$ for $7 \mathrm{~min}$. PCR products of 650 $\mathrm{bp}$ in molecular weight sizes were then purified and sequenced. Closely related sequences of the isolates were retrieved from the NCBI GenBank database. A neighbour-joining tree was constructed and the distances between the sequences were calculated from the models of Jukes and Cantor (1969).

\section{Trial PCP biodegradation in liquid medium}

The best PCP-tolerant fungal isolate that showed high growth rate and high tolerance towards PCP was selected for PCP degradation in glucose minimal (GM) liquid medium (Ryu et al. 2000). The GM medium used contained $\left(\mathrm{g} \mathrm{L}^{-1}\right): 1.0$ $\mathrm{K}_{2} \mathrm{HPO}_{4}, 0.01 \mathrm{ZnSO}_{4} .7 \mathrm{H}_{2} \mathrm{O}, 0.005 \mathrm{CuSO}_{4} .5 \mathrm{H}_{2} \mathrm{O}$, $0.5 \mathrm{MgSO}_{4} .7 \mathrm{H}_{2} \mathrm{O}, 0.01 \mathrm{FeSO}_{4} .7 \mathrm{H}_{2} \mathrm{O}, 0.5 \mathrm{KCl}, 10$ glucose and $3.0 \mathrm{NaNO}_{3}$ as the sole source of nitrogen. The $\mathrm{pH}$ of the liquid medium was adjusted to 5.5 before autoclaving at $121^{\circ} \mathrm{C}$ for 15 min. Two pieces of agar plugs ( $5 \mathrm{~mm}$ in diameter) of a four days old culture grown on MEA at $28^{\circ} \mathrm{C}$ were used as inoculums in each of the $20 \mathrm{~mL}$ liquid medium in $100 \mathrm{~mL}$ flasks. The cultures were grown under static condition for a period of $24 \mathrm{~h}$ at room temperature before PCP dissolved in acetone was added to the culture medium $(\mathrm{pH}$ $5.13 \pm 0.09$ ) to a final concentration of $20 \mathrm{mg} \mathrm{L}^{-1}$. Flask containing PCP but with no fungal inoculums was prepared as control. All the experiments were done in triplicate. The biodegradation experiment was done for a period of 15 days at room temperature with sampling at a three days time interval. The entire content of the culture flask was harvested during sampling in order to determine the residual PCP concentration.

\section{Residual PCP extraction and quantification}

Residual PCP in the GM liquid medium was extracted using $n$-hexane. The entire culture was centrifuged at $6000 \mathrm{rpm}$ for $10 \mathrm{~min}$ to separate the fungal mycelium from the liquid culture. The $\mathrm{pH}$ of the supernatant was brought to $\mathrm{pH} 2.0$ by the addition of 3M HCL. Using a separating funnel, PCP in the acidified supernatant was then extracted three times with $10 \mathrm{~mL}$ of hexane. Sufficient amount of anhydrous sodium sulfate was then added to the hexane organic phase to dry the hexane of any aqueous solution. The hexane was left to dry in the fume hood at room temperature. Residual PCP was then re-dissolved in $3.0 \mathrm{~mL}$ of $0.5 \mathrm{M} \mathrm{NaOH}$ and quantified using spectrophotometer with a detection limit for PCP of $0.1 \mu \mathrm{g} / \mathrm{ml}$ at an absorbance of $320 \mathrm{~nm}$ (Mueller et al. 1991; Tam et al. 1999). PCP adsorbed on the fungal biomass was also extracted according to the method of Tomasini et al. (2001) and quantified similarly using spectrophotometer. Briefly, the fungal mycelium was sonicated $5.0 \mathrm{~mL}$ of $0.2 \mathrm{M}$ carbonate buffer ( $\mathrm{pH}$ 10.7) for $10 \mathrm{~min}$. The fungal mycelium was then separated from the buffer by centrifugation at $6000 \mathrm{rpm}$ for $10 \mathrm{~min}$. The collected buffer was acidified to $\mathrm{pH} 2.0$ with $3 \mathrm{M}$ $\mathrm{HCl}$ and PCP was extracted three times each with $4.0 \mathrm{~mL}$ of hexane. Total residual PCP was reported as the total amount of PCP in the supernatant plus the total amount adsorbed on the mycelia (in relative to the maximum that was recovered using the stated extraction method with an extraction efficiency of $84.4 \%$ ). The percentage of PCP degradation was calculated using the formula:

$$
\text { PCP degradation }(\%)=\frac{t c_{t}-t t_{t}}{t c_{t}} \times 100 \%
$$


Where $t c_{t}=$ Total residual PCP in PCP abiotic control flask (with no fungal inoculum) at time $\mathrm{t}$ $t t_{t}=$ Total residual PCP in PCP treatment flask added with fungal inoculum at time $\mathrm{t}$

\section{RESULTS AND DISCUSSION}

\section{Fungal isolation}

A total number of 33 fungal isolates were isolated from the aging sawdust sample. Only fungal isolates that showed high tolerance towards PCP were further characterized and identified.

\section{PCP tolerance of the isolated fungi}

All the 33 fungal isolates were screened for their ability to grow and tolerate PCP at concentrations ranging from 0 to $20 \mathrm{mg} \mathrm{L}^{-1}$ on solid agar plate. Results showed that all of the fungal isolates exhibited different degrees of sensitivity towards PCP. Due to the toxic effect of PCP, the maximum mycelial growth rate recorded for all of the isolates were greatly reduced in the presence of PCP and further reduced with increasing PCP concentrations. The fungal isolates were able to grow in the presence of $5 \mathrm{mg} \mathrm{L}^{-1}$ of PCP and up to 27 isolates were able to grow at $20 \mathrm{mg} \mathrm{L}^{-1}$ of PCP (data not shown). Among these 33 isolates, isolate SD12 even though not the fastest growing isolate, showed the highest mycelial growth rate on all the different PCP concentration tested.

Seven fungal isolates that showed high growth rate and tolerance towards PCP were selected and tested at higher PCP concentration of 50 and 100 $\mathrm{mg} \mathrm{L}^{-1}$. From the results obtained, four isolates (SD12, SD14, SD19 and SD20) grew tolerating up to $100 \mathrm{mg} \mathrm{L}^{-1}$ of PCP (Table 1, Fig. 1).

Table 1 -The maximum mycelia extension rate recorded of the seven selected fungal isolates from sawdust within 14 days at higher PCP concentration.

\begin{tabular}{cccc}
\hline \multirow{2}{*}{$\begin{array}{c}\text { Fungal } \\
\text { Isolates }\end{array}$} & \multicolumn{3}{c}{$\begin{array}{c}\text { Maximum mycelial extension rate }\left(\mathbf{m m ~ d a y}^{-\mathbf{1}}\right) \\
\text { at higher concentration of } \mathbf{P C P}\left(\mathbf{m g ~ L}^{\mathbf{- 1}}\right)\end{array}$} \\
\cline { 2 - 4 } & $\mathbf{0}$ & $\mathbf{5 0}$ & $\mathbf{1 0 0}$ \\
\hline SD11 & $50.5 \pm 0.6$ & $1.70 \pm 0.5$ & 0.0 \\
$\mathrm{SD12}$ & $\mathbf{3 4 . 3} \pm \mathbf{0 . 5}$ & $\mathbf{1 1 . 3} \pm \mathbf{2 . 0}$ & $\mathbf{1 0 . 0} \pm \mathbf{0 . 8}$ \\
$\mathrm{SD14}$ & $\mathbf{5 0 . 9} \pm \mathbf{1 . 0}$ & $\mathbf{6 . 8} \pm \mathbf{0 . 0}$ & $\mathbf{4 . 5 0} \pm \mathbf{1 . 4}$ \\
$\mathrm{SD19}$ & $\mathbf{4 3 . 8} \pm \mathbf{0 . 4}$ & $\mathbf{8 . 3} \pm \mathbf{0 . 8}$ & $\mathbf{4 . 5 0} \pm \mathbf{0 . 8}$ \\
$\mathrm{SD20}$ & $\mathbf{4 1 . 0} \pm \mathbf{0 . 9}$ & $\mathbf{6 . 5} \pm \mathbf{0 . 5}$ & $\mathbf{4 . 2} \pm \mathbf{0 . 5}$ \\
$\mathrm{SD} 30$ & $40.3 \pm 0.8$ & 0.0 & 0.0 \\
SD32 & $43.0 \pm 0.9$ & $2.0 \pm 0.0$ & 0.0 \\
\hline Results are & represented as & means \pm standard deviation of three
\end{tabular}
replica cultures

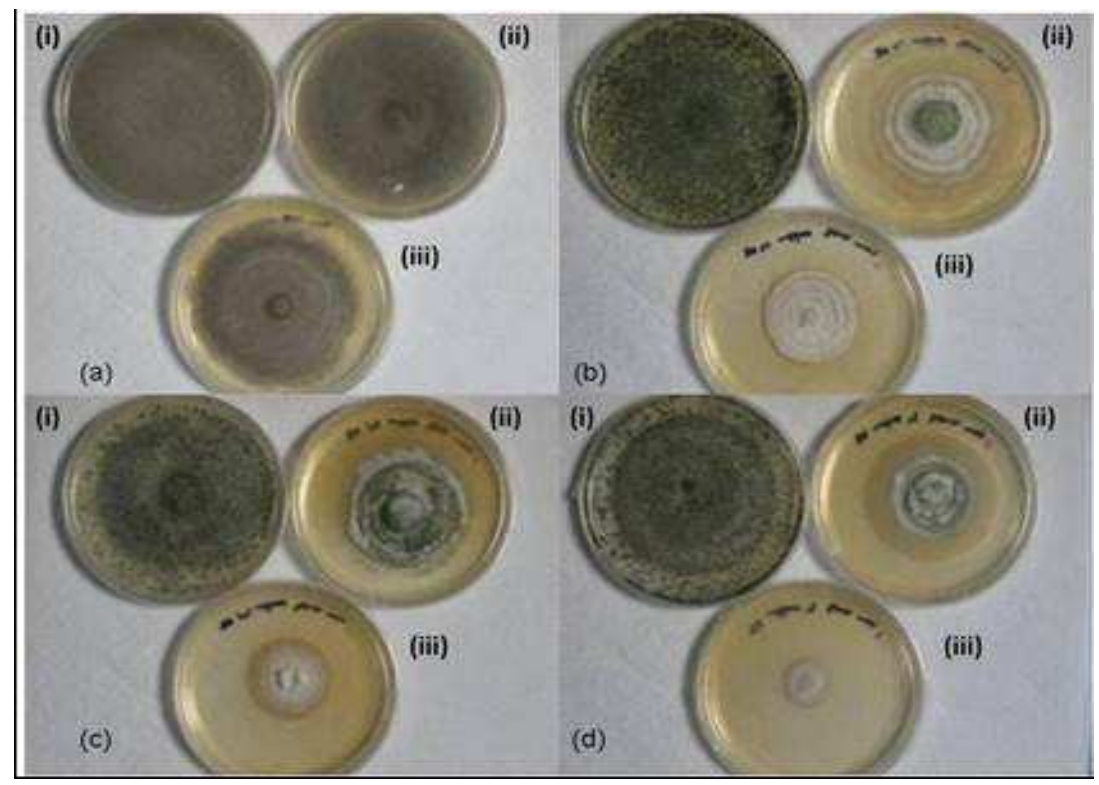

Figure 1 - Growth of fungal isolates (a) SD12 (b) SD14 (c) SD19 and (d) SD20 from sawdust on YMPG agar containing (i) $0 \mathrm{mg} \mathrm{L}^{-1}$ (ii) $50 \mathrm{mg} \mathrm{L}^{-1}$ and (iii) $100 \mathrm{mg} \mathrm{L}^{-1}$ of PCP concentration after 14 days.

Among these four isolates, isolate SD12 showed the highest mycelial extension rate, which was 10 $\mathrm{mm} \mathrm{day}^{-1}$ at $100 \mathrm{mg} \mathrm{L}^{-1}$ of PCP. This was followed by SD14 and SD19, both with $4.5 \mathrm{~mm} \mathrm{day}^{-1}$ and 
SD20 with $4.2 \mathrm{~mm} \mathrm{day}{ }^{-1}$. Besides showing high growth rate in the presence of PCP, isolate SD12 was also the most tolerant towards PCP among the four fungal isolates. The increase in PCP concentration from 50 to $100 \mathrm{mg} \mathrm{L}^{-1}$ only caused a minor reduction to the growth rate of isolate SD12. The maximum mycelial extension rate obtained for the isolate SD12 at $100 \mathrm{mg} \mathrm{L}^{-1}$ of PCP was also higher as compared to the zygomycete, Rhizopus nigricans that grew at a rate of $6.6 \mathrm{~mm} \mathrm{day}{ }^{-1}$ at $100 \mathrm{mg} \mathrm{L}^{-1}$ of PCP (Tomasini et al. 2001).

According to Lamar and co-workers (1990), having a microorganism that is capable of tolerating high contaminant concentrations would be a distinct advantage for the bioremediation of highly contaminated media. Fungal isolates SD12, SD14, SD19 and SD20 showed an interesting potential for PCP bioremediation. Okeke and coworker (1994) studied the growth of fungus $L$. edodes that was repressed by PCP at only $15 \mathrm{mg}$ $\mathrm{L}^{-1}$ in agar but was able to tolerate up to $200 \mathrm{mg}$ $\mathrm{kg}^{-1}$ of PCP in the soil. P. chrysosporium and $P$. sordida that were able to grow at $25 \mathrm{ppm}$ of PCP (Lamar et al. 1990) were able to grow and deplete 88 to $91 \%$ of PCP in a field soil with initial concentrations from 250 to $400 \mathrm{mg} \mathrm{kg}^{-1}$ of PCP (Lamar and Dietrich 1990). Fungal isolate, especially SD12, which grew and tolerated up to $100 \mathrm{mg} \mathrm{L}^{-1}$ of PCP in agar might be able to tolerate an even higher concentration of $\mathrm{PCP}$ in the soil when applied for bioremediation.

\section{Scanning electron microscopy (SEM) of PCP tolerant fungal isolates}

Isolate SD12, SD14, SD19 and SD20 were selected for further examination under SEM to see how well these isolate could tolerate the biocidal effect of PCP. SEM results showed that the presence of high PCP concentration $\left(100 \mathrm{mg} \mathrm{L}^{-1}\right)$ caused various degree of morphological changes to the hyphae structure of the tested fungal isolates. At high PCP concentration, the hyphae of all the four isolates, except for isolate SD12 appeared to collapse and had a wrinkles type of appearance as compared to the control (Fig. 2). Not many changes, however, were observed for the hyphae of isolate SD12, which appeared to be fine and smooth. Only minor collapse to the sporangiophores and sporangiola of isolate SD12 was observed at $100 \mathrm{mg} \mathrm{L}^{-1}$ of PCP.
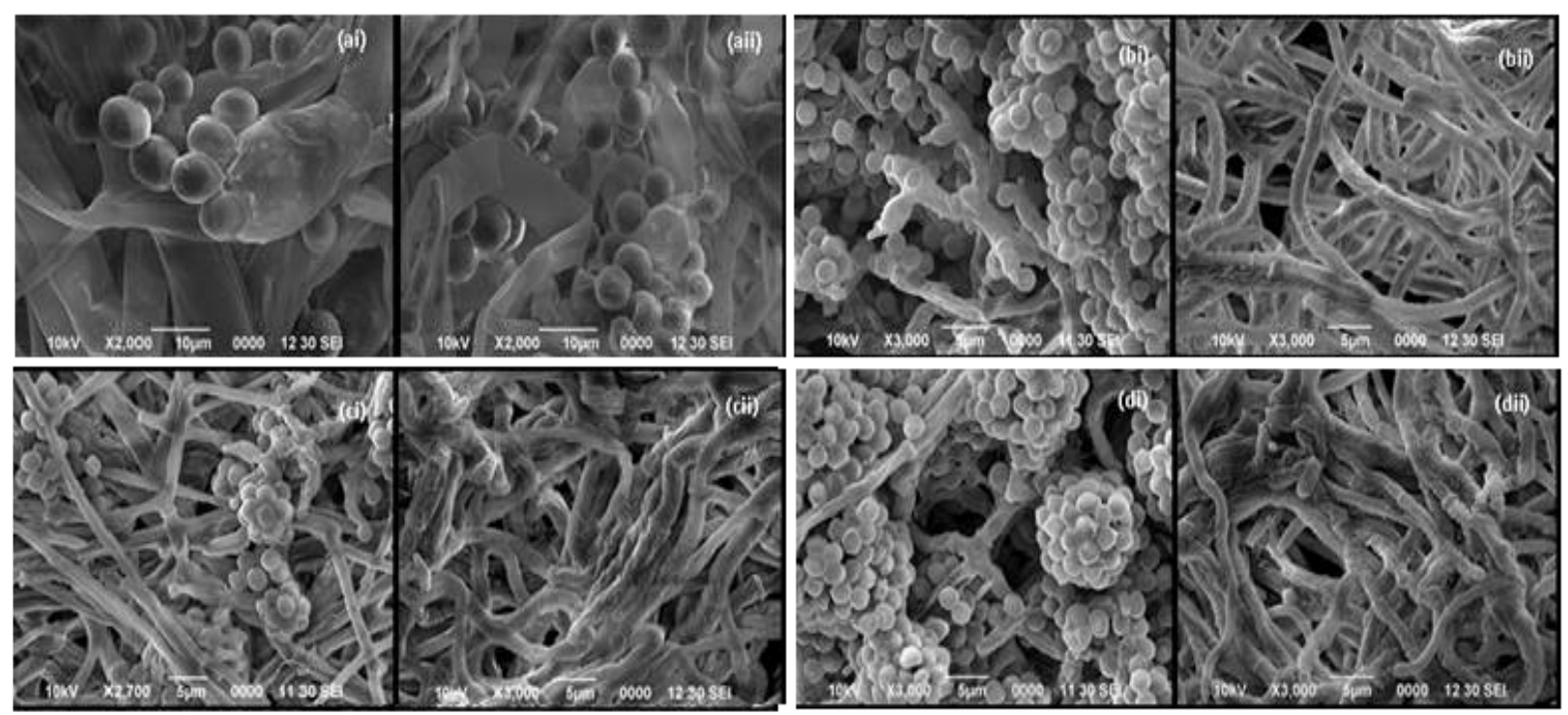

Figure 2 - SEM micrographs of isolate (a) SD12, (b) SD14, (c) SD19 and (d) SD20 grown for 14 days on agar medium containing (i) $0 \mathrm{mg} \mathrm{L}^{-1}$ of PCP as control and (ii) $100 \mathrm{mg} \mathrm{L}^{-1}$ of PCP.

Besides altering the structure of fungal hyphae, PCP also causes the collapse of fungal spores. From the four fungal isolates examined using SEM, isolate SD12 was the only isolate that still produced sporangiospores at $100 \mathrm{mg} \mathrm{L}^{-1}$ of PCP. Among the produced sporangiola, however, some of the sporangiola were collapsed and wrinkled (Fig. 2ii). PCP has been known to strongly inhibit spore germination at only just $4.0 \mathrm{mg} \mathrm{L}^{-1}$ even in the cultures of highly efficient PCP degrading white-rot fungus $P$. chrysosporium (Mileski et al. 1988). The ability of PCP to cause fungal spores to 
collapse as observed among some of the sporangiola produced by the isolate SD12 might be one of the mechanisms of PCP to inhibit the fungal spore germination. PCP has been shown to prevent the spores from germinating (Carvalho et al. 2009), which, based on the present data, might be related to the collapse of the spores caused by PCP.

Among the four fungal isolates capable of tolerating up to $100 \mathrm{mg} \mathrm{L}^{-1}$ of PCP, isolate SD12 showed the least structural damage at high PCP concentration. Not only it tolerated the high concentration of PCP, it was also the fastest growing isolate in the presence of PCP. This, therefore, showed that isolate SD12 was a strong PCP tolerating fungal isolate. The other three fungal isolates were also strong PCP tolerating fungi as well. Even with the damage done by the $\mathrm{PCP}$, these fungal isolates were still able to grow at high PCP concentration.

\section{Fungal characterisation and identification}

Morphological characterisation of the four PCP tolerant isolates showed that isolate SD12 was a species of the genera Cunninghamella (Zygomycetes) while isolate SD14, SD19 and SD20 belonged to Trichoderma sp (Ascomycetes) (Table 2).

Table 2 - Macroscopic and microscopic characterization of the four PCP tolerant fungal isolates.

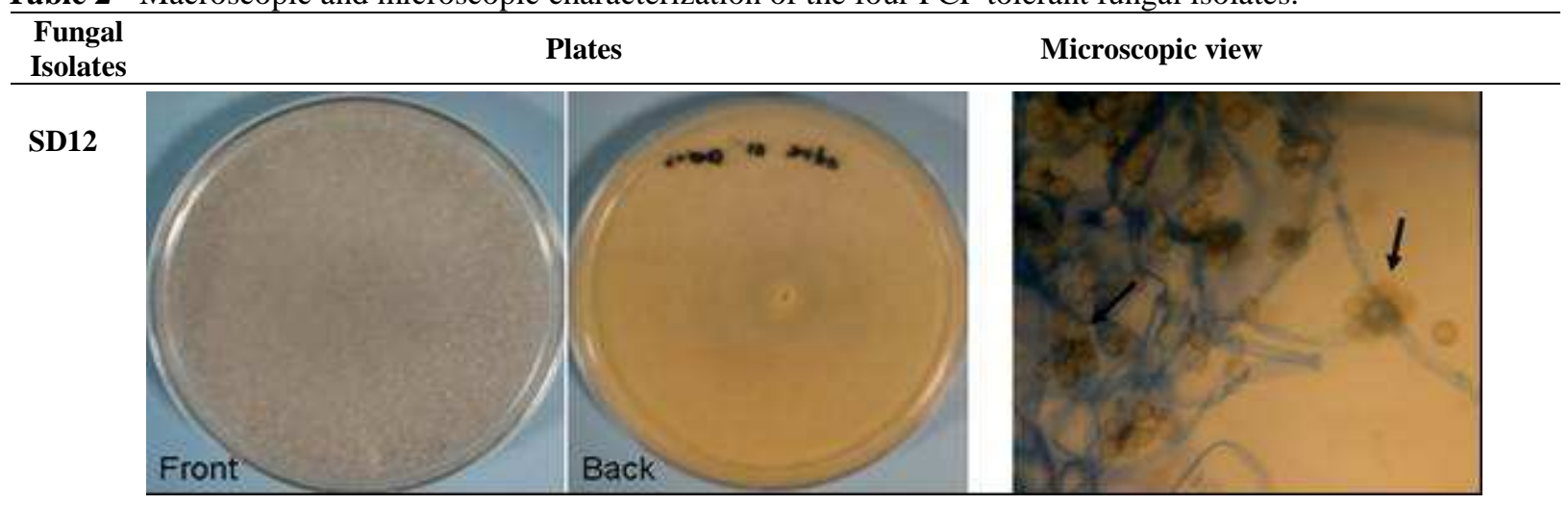

Fast growing colony that fill up $90 \mathrm{~mm}$ Petri dish in 4-5 days. Woolly or cottony mycelial mat formed were white at first but becoming dark grey with sporangiola development. Aerial mycelium form strands that reached the cover of the petri dish. No pigment production and underside of colony is slightly yellowish (color of growth medium)

\section{Magnification: $600 \mathrm{x}$}

Apex of mature sporangiophores with clusters of attached globose to ovoid sporangiola (Arrow). Coenocytic hyphae.

Presumed as Cunninghamella spp.

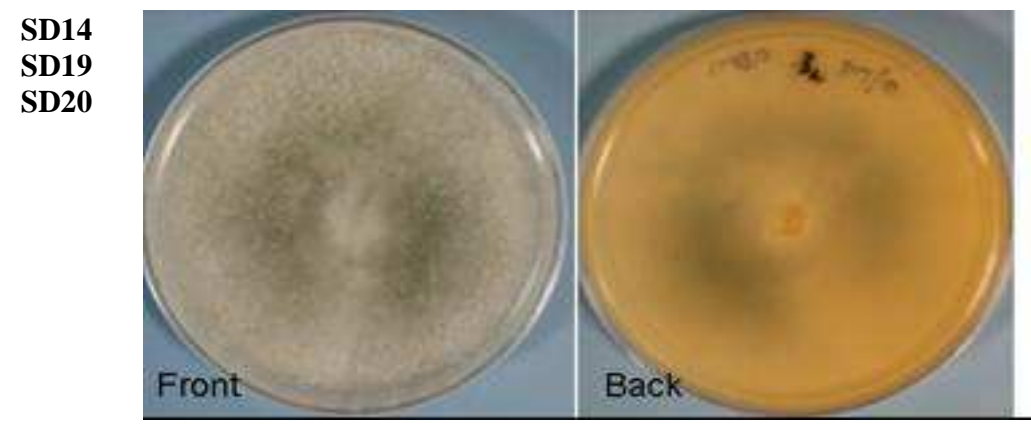

Colony was fast growing and the mycelium covered the whole petri dish in 4 days. Aerial mycelium was first white but become light green upon conidiation. Conidiation causes the white fluffy mycelium to clump, forming thick fluffy tufts which cover mostly the margin of the plate. Mycelium was also slightly raised as it spread from the centre. No pigment production and the underside of the colony is the colour of the growth medium.

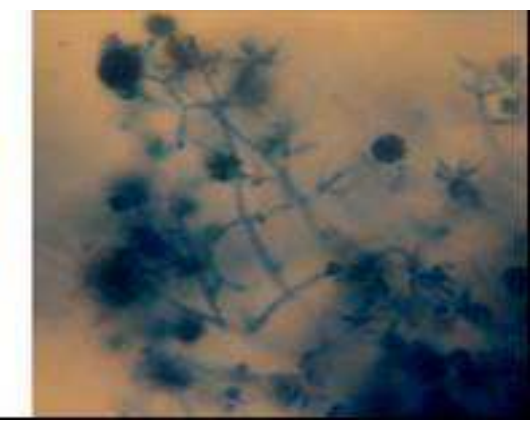

Magnification: 600x Conidiophores are repeatedly branched, bearing clusters of divergent, irregularly bent, flask shaped phialides. Clustered conidia were formed at the tips of the phialides. Septate hyphae.

Presumed as Trichoderma spp. 
Molecular identification of the four PCP tolerant fungal isolates further confirmed that these isolates were Cunninghamella and Trichoderma species. The phylogenetic tree constructed based on the ITS sequences of the four isolates indicated that isolate SD14 was close to Hypocrea lixii, teleomorph of Trichoderma harzianum, with up to
99\% sequence similarity. SD19 and SD20 showed 99\% sequence similarity with Trichoderma piluliferum and were closely related with Trichoderma aureoviride, also with 99\% sequence similarity. Isolate SD12 used as out group showed 98\% sequence similarity with Cunninghamella bainieri (Fig. 3).

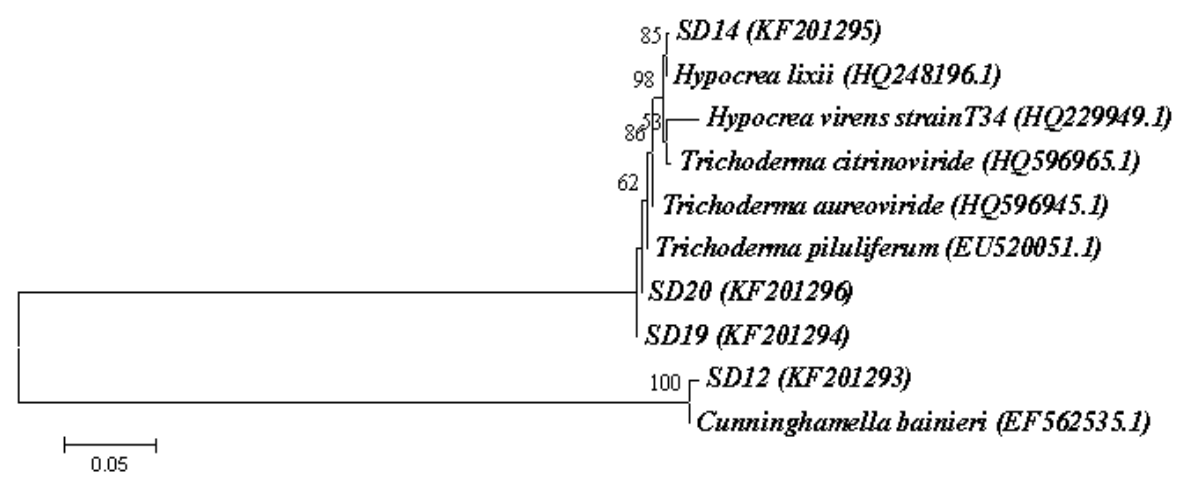

Figure 3 - Neighbour-joining tree from ITS sequences showing the relationship between the four PCP tolerance fungi from sawdust and closely related sequences of the isolates retrieved from the GenBank (accession number). Bootstrap value $>50 \%$ (1000 replicates) are shown at the branches. Bar $=5$ nucleotide substitutions per 100 nucleotides.

Trichoderma species are free living fungi that are commonly found in soil, root and foliar environments. These fungi also colonize woody and herbaceous plant materials, in which the sexual teleomorph has most often been found (Harman et al. 2004). Trichoderma species, especially $T$. harzianum and $T$. virens have been well known for their application as an effective biological control agent against several soil-borne phytopathogenic fungi and for the commercial production of cellulase by $T$. reesei (Samuels 1996; Verma et al. 2007). Studies have also shown the applicability of the soil borne ascomycetes such as $T$. viride and $T$. harzianum for the degradation of various xenobiotics, including phenanthrene, pyrene, endosulfan, cyanide and pentachlorophenol (Cserjesi 1967; Katayama and Matsumura 1993; Ravelet et al. 2000; ChavezGomez et al. 2003; Ezzi and Lynch 2005). Trichoderma virgatum has been reported to reduce up to $95 \%$ of PCP by methylation of PCP to a less toxic compound (Cserjesi and Johnson 1972). Duncan and Deverall (1964) have also reported on a less recovery of PCP from Trichoderma treated wood and found a decreasing activity of PCP against this fungus. They concluded that
Trichoderma was able to degrade pentachlorophenol.

Different from Trichoderma species, however, Cunninghamella species have been used widely as a microbial model of mammalian metabolism of various pharmaceutical drugs and xenobiotics due to their ability to metabolise these compounds in a manner similar to that in the mammals (Abourashed et al. 1999; Asha and Vidyavathi 2009). Several species of this zygomycetes, normally found in the soil such as Cunninghamella elegans, Cunninghamella blakesleeana and $C$. bainieri have been used to oxidize, transform or metabolize various drugs (propranolol, warfarin, naproxen, verapamil and flutamide), phenylurea herbicide (chlortoluron, diuron and isoproturon) and organopollutants such as poly aromatic hydrocarbons (anthracene, phenanthrene and fluorine) (Ferris et al. 1973; Cerniglia and Yang 1984; Foster et al. 1989; Rizzo and Davis 1989; Vroumsia et al. 1996; Garon et al. 2000; Zhong et al. 2003; Sun et al. 2004; Amadio and Murphy 2011). Cunninghamella species have also been reported to degrade organochlorine such as PCP (Seigle-Murandi et al. 1992). Seigle-Murandi and co-workers (1995) reported that C. bainieri was able to degrade $13 \%$ of PCP in just 6 days after 
PCP initial addition $\left(1 \mathrm{~g} \mathrm{~L}^{-1}\right)$ in glucose containing GS liquid medium.

\section{Trial PCP biodegradation in liquid medium by isolate SD12}

Cunninghamella sp. UMAS SD12 that showed the highest growth rate and tolerance towards PCP was tested for its ability to degrade PCP in glucose minimal liquid medium. The fungus was allowed to grow for $24 \mathrm{~h}$ before PCP was added to a final concentration of $20 \mathrm{mg} \mathrm{L}^{-1}$ (Day 0). Results showed that the isolate SD12 removed up to $51.7 \%$ of PCP after 15 days (Fig. 4). PCP in the liquid medium was gradually depleted by the isolate SD12 from $14.5 \mathrm{mg} \mathrm{L}^{-1}$ on day 0 to 10.4 $\mathrm{mg} \mathrm{L}{ }^{-1}$ on day 6 and finally to $6.6 \mathrm{mg} \mathrm{L}^{-1}$ on day 15. PCP concentration in the abiotic control flask with no fungal inoculum decreased progressively throughout the 15 days of incubation but the decrease was only $3.1 \mathrm{mg} \mathrm{L}^{-1}$ of PCP. The ability of isolate SD12 to tolerate high PCP concentration and at the same time degrade PCP, therefore, highlighted the potential applicability of the fungal isolates from sawdust for bioremediation of PCP contaminated sites.

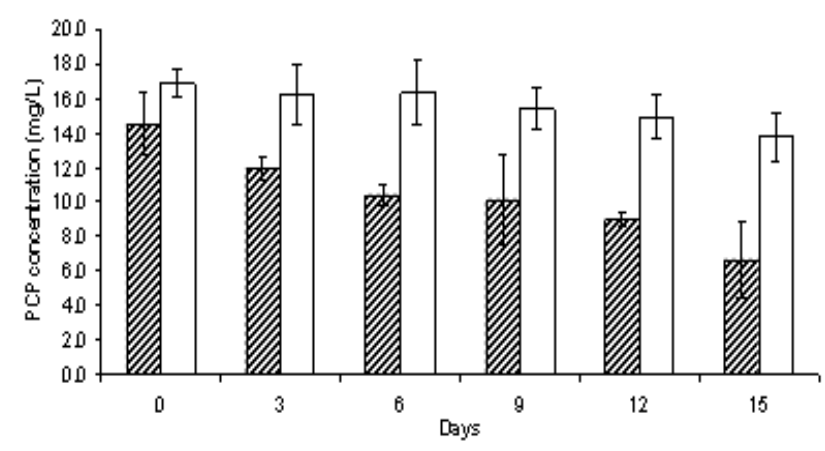

Figure 4 - Depletion of PCP by fungal isolates SD12 within a period of 15 days in glucose minimal liquid medium supplemented with $20 \mathrm{mg} \mathrm{L}^{-1}$ of PCP. PCP concentration in the abiotic control flask (with no fungal inoculate) is indicated by an empty bar. Each data is represented by the mean of three replicates.

Szewczyk et al (2003) have also previously reported the isolation of zygomycete, Mucor ramosissimus from contaminated site that was capabale of tolerating and transforming $10 \mathrm{mg} / \mathrm{L}$ of PCP to tetrachlorohydroquinone (TCHQ). Leon-Santiesteban et al (2008) reported the isolation of tyrosinase and peroxidase producing zygomycete, Rhizopus oryzae from PCP contaminated soil that tolerated and removed $90 \%$ of initial PCP concentration (12.5\%). Carvalho et al (2009) also showed that besides basidiomycetes or white rot fungi, zygomycetes such as Cunninghamella sp. UMAS SD12 also tolerated and degraded PCP. Further studies on the metabolites produced by the isolate SD12 during PCP degradation would be crucial in order to facilitate in identifying the possible enzymes and PCP degradation pathway used by the isolates to degrade PCP.

\section{CONCLUSION}

The results demonstrated the successful isolation and characterization of four PCP-tolerant fungal isolates. SEM study of the isolates grown on PCP showed that high PCP concentration resulted the collapse of fungal hyphae and spores. Despite that, these fungal isolates were able to grow. The PCP tolerance fungi were identified as Cunninghamella and Trichoderma sp. Cunninghamella sp. UMAS SD12 showed the highest tolerance towards PCP and its degradation in liquid medium in 15 days.

\section{ACKNOWLEDGEMENTS}

This research project was supported by Universiti Malaysia Sarawak and financially funded by Ministry of Higher Education Malaysia (MoHE) under the Fundamental Research Grant Scheme (FRGS) (E14099/F07/69/769/2010(50).

\section{REFERENCES}

Abourashed EA, Clark AM, Hufford CD. Microbial models of mammalian metabolism of xenobiotics: An updated review. Curr Med Chem. 1999; 6: 359-374.

Akpomie OO, Ubogun E, Ubogun M. Determination of the cellulolytic activities of microorganisms isolated from poultry litter for sawdust degradation. J Environ Sci Water Resour. 2013; 2: 062-066.

Amadio J, Murphy CD. Production of human metabolites of the anti-cancer drug flutamide via biotransformation in Cunninghamella species. Biotechnol Lett. 2011; 33: 321-326.

Asha S, Vidyavathi M. Cunninghamella-a microbial model for drug metabolism studies-a review. Biotech Adv. 2009; 27: 16-29. 
Bianchi A, Zambonelli A, D’Aulerio AZ, Bellesia F. Ultrastructural studies of the effects of Allium sativum on phytopathogenic fungi in vitro. Plant Dis. 1997; 81: 1241-1246.

Carvalho MB, Martins I, Leitao MC, Garcia H, Rodrigues C, Romao, VS, Mclellan I, Hursthouse A, Pereira CS. Screening pentachlorophenol degradation ability by environmental fungal strains belonging to the phyla ascomycota and zygomycota. $J$ Ind Microbiol Biotechnol. 2009; 36: 1249-1256.

Cerniglia CE, Yang SK. Stereoselective metabolism of anthracene and phenanthrene by the fungus Cunninghamella elegans. Appl Environ Microbiol. 1984; 47: 119-124.

Chavez-Gomez B, Quintero R, Esparza-Garcia F, Mesta-Howard AM, Zavala Diaz de la Serna FJ, Hernandez-Rodriguez CH, Gillen T, Poggi-Varaldo HM, Barrera-Cortes J, Rodriguez-Vazquez R. Removal of phenanthrene from soil by co-cultures of bacteria and fungi pregrown on sugarcane bagasse pith. Bioresour Technol. 2003; 89: 177-183.

Cserjesi AJ. The adaptation of fungi to pentachlorophenol and its biodegradation. Can J Microbiol. 1967; 13: 1243-1249.

Cserjesi AJ, Johnson EL. Methylation of pentachlorophenol by Trichoderma virgatum. Can J Microbiol. 1972; 18: 45-49.

Cubero OF, Crespo A, Fatehi J, Bridge PD. DNA extraction and PCR amplification method suitable for fresh, herbarium-stored, lichenized and other fungi. Plant Syst Evol. 1999; 216: 243-249.

Demers PA, Davies HW, Friesen MC, Hertzman C, Ostry A, Hershler R, Teschke K. Cancer and occupational exposure to pentachlorophenol and tetrachlorophenol (Canada). CCC. 2006; 17: 749-758.

Duncan CG, Deverall, FJ. Degradation of wood preservatives by fungi. App. Environ Microbiol. 1964; 12: 57-62.

Ezzi MI, Lynch JM. Biodegradation of cyanide by Trichoderma spp. and Fusarium spp. Enzyme Microb Technol. 2005; 36: 849-854.

Ferris JP, Fasco MJ, Stylianopoulou FL, Jerina DM, Daly JW, Jeffrey AM. Monooxygenase activity in Cunninghamella bainieri: Evidence for a fungal system similar to liver microsomes. Arch Biochem Biophys. 1973; 156: 97-103.

Fisher B. Pentachlorophenol: toxicology and environmental fate. J Pesticide Reform. 1991; 11 (1): 2-5.

Foster BC, Buttar HS, Qureshi SA, McGilveray IJ. Propranolol metabolism by Cunninghamella bainieri. Xenobiotica. 1989; 19: 539-546.

Garon D, Krivobok S, Seigle-Murandi F. Fungal degradation of fluorene. Chemosphere. 2000; 40: 9197.
Ge JC, Pan JL, Fei ZL, Wu GH, Giesy JP. Concentrations of pentachlorophenol (PCP) in fish and shrimp in Jiangsu Province, China. Chemosphere. 2007; 69: 164-169.

Giraud F, Guiraud P, Kadri M, Blake G, Steiman R. Biodegradation of anthracene andfluoranthene by fungi isolated from an experimental constructed wetland for wastewater treatment. Water Res. 2001; 35: 4126-4136.

Harman GE, Howell CR, Viterbo A, Chet I, Lorito M. Trichoderma species-opportunistic, avirulent plant symbionts. Nature Rev Microbiol. 2004; 2: 43-56.

IARC. IARC monographs on the evaluation of carcinogenic risks to humans 71: Re-evaluation of some organic chemicals, hydrazine and hydrogen peroxide, Lyon, France. World Health Organization, International Agency for Research on Cancer, 1999.

Jukes TH, Cantor CR. Evolution of protein molecules. In: Munro HN (Ed.). Mammalian Protein Metabolism (Vol. 3). Academic Press, New York, USA, 1969; p.21-132.

Katayama A, Matsumura F. Degradation of organochlorine pesticides, particularly endosulfan, by Trichoderma harzianum. Environ Toxicol Chem. 1993; 12: 1059-1065.

Keither LH. Teilard WA. Priority pollutants. I. A perspective view. Environ Sci Technol. 1979; 13: 416-423.

Kitunen VH, Salkinoja-Salonen MS. Soil contamination at abandoned sawmill areas. Chemosphere. 1990; 20: 1671-1677.

Lamar RT, Dietrich DM. In situ depletion of pentachlorophenol from contaminated soil by Phanerochaete spp. Appl Environ Microbiol. 1990; 56: 3093-3100.

Lamar RT, Larsen MJ, Kirk K. Sensitivity to and degradation of pentachlorophenol by Phanerochaete spp. Appl Environ Microbiol. 1990; 56: 3519-3526.

Lennox JA, Abriba C, Alabi BN, Akubuenyi FC. Comparative degradation of sawdust by microorganisms isolated from it. Afr J Microbiol Res. 2010; 4: 1352-1355.

Leon-Santiesteban H, Bernal R, Fernandez FJ, Tomasini A. Tyrosinase and peroxidase production by Rhizopus oryzae strain ENHE obtained from pentachlorophenol-contaminated soil. J Chem Tech Biot, 2008; 83: 1394-1400

Manoch L, Jeamjitt O, Eamvijarn A, Dethoup T, Kokaew J, Paopun Y, Poochinya P, Umrung P. Light and SEM studies on leaf litter fungi. J. Microsc. Soc. Thailand. 2008; 22: 56-59.

McAllister KA, Lee H, Trevors JT. Microbial degradation of pentachlorophenol. Biodegradation. 1996; $7: 1-40$. 
McLean D, Eng A, Dryson E, Walls C, Harding E, Wong KC, Cheng S, Mannetje A, Ellison-Loschmann L, Slater T, Shoemack P, Pearce N. Morbidity in former sawmill workers exposed to pentachlorophenol (PCP): A cross-sectional study in New Zealand. Am J Ind Med. 2009; 52: 271-281.

Mileski GJ, Bumpus JA, Jurek MA, Aust SD. Biodegradation of pentachlorophenol by the white rot fungus Phanerochaete chrysosporium. Appl Environ Microbiol. 1988; 54: 2885-2889.

Mueller JG, Middaugh DP, Lantz SE, Chapman PJ. Biodegradation of creosote and pentachlorophenol in contaminated groundwater: chemical and biological assessment. Appl Environ Microbiol. 1991; 57: 1277 1285.

Novotny C, Erbanova P, Sasek V, Kubatova A, Cajthaml T, Lang E, Krahl J, Zadrazil F. Extracellular oxidative enzyme production and PAH removal in soil by exploratory mycelium of white rot fungi. Biodegradation. 1999; 10: 159-168.

Nwodo-Chinedu S, Okochi VI, Smith HA, Omidiji O. Isolation of cellulolytic microfungi involved in woodwaste decomposition: prospects for enzymatic hydrolysis of cellulosic wastes. Int J Biomed Health Sci. 2005; 1(2): 2): 41-51.

Okeke BC, Paterson A, Smith JE, Watson-Craik IA. Relationships between ligninolytic activities of Lentinula spp. and biotransformation of pentachlorophenol in sterile soil. Lett Appl Microbiol. 1994; 19: 284-287.

Persson Y, Lundstedt S, Oberg L, Tysklind M. Levels of chlorinated compounds (CPs. PCPPs,PCDEs, PCDFs and PCDDs) in soils at contaminated sawmill sites in Sweden. Chemosphere. 2007; 66: 234-242.

Proudfoot AT. Pentachlorophenol poisoning. Toxicol Rev. 2003; 22: 3-11.

Ravelet C, Krivobok S, Sage L, Steiman R. Biodegradation of pyrene by sediment fungi. Chemosphere 2000; 40: 557-563.

Rizzo JD, Davis PJ. Microbial models of mammalian metabolism: Conversion of warfarin to 4'hydroxywarfarin using Cunninghamella bainieri. J Pharm Sci. 1989; 78: 183-189.

Ryu WR, Shim SH, Jang MY, Jeon YJ, Oh KK, Cho $\mathrm{MH}$. Biodegradation of white rot fungi under ligninolytic and nonligninolytic conditions. Biotechnol Bioproc. E. 2000; 5: 211-214.

Samuels GJ. Trichoderma: a review of biology and systematics of the genus. Mycol Res.1996; 100: 923935.
Seigle-Murandi F, Steiman R, Benoit-Guyod JL, Guiraud P. Biodegradation of pentachlorophenol by micromycetes. 1. Zygomycetes. Environ Toxicol Water Qual. 1992; 7: 125-139.

Seigle-Murandi F, Toe A, Benoit-Guyod JL, Steiman R, Kadri M. Depletion of pentachlorophenol by deuteromycetes isolated from soil. Chemosphere. 1995; 31: 2677-2686.

Sun L, Huang HH, Liu L, Zhong DF. Transformation of verapamil by Cunninghamella blakesleeana. Appl Environ Microbiol. 2004; 70: 2722-2727.

Szewczyk R, Bernat p, Milczarek K, Dlugonski J. Application of microscopic fungi isolated from polluted industrial areas for polycyclic aromatic hydrocarbons and pentachlorophenol reduction. Biodegradation, 2003; 14: 1-8.

Tam S, Johnson SA, Graham A. The effect of organic structures on pentachlorophenol adsorption on soil. Water Air Soil Pollut. 1999; 115: 337-346.

Tomasini A, Flores V, Cortes D, Barrios-Gonzalez J. An isolate of Rhizopus nigricans capable of tolerating and removing pentachlorophenol. World J Microbiol Biotechn. 2001; 17: 201-205.

Tuomela M, Lyytikainen M, Oivanen P, Hatakka A. Mineralization and conversion of pentachlorophenol (PCP) in soil inoculated with the white-rot fungus Trametes versicolor. Soil Biol Biochem. 1999; 31: 65-74.

Verma M, Brar SK, Tyagi RD, Surampalli RY, Valero JR. Antagonistic fungi, Trichoderma spp.: Panoply of biological control. Biochem Eng J. 2007; 37: 1-20.

Vroumsia T, Steiman R, Seigle-Murandi F, BenoitGuyod JL, Khadrani A. Biodegradation of three substituted phenylurea herbicides (chlortoluron, diuron, and isoproturon) by soil fungi. A comparative study. Chemosphere. 1996; 33: 2045-2056.

White TJ, Bruns T, Lee S, Taylor J. Amplification and direct sequencing of fungal ribosomal RNA genes for phylogenetics. In: Innis MA, Gelfand DH, Sninsky JJ, White TJ, (eds.) PCR Protocols: A Guide to Methods and Applications, Academic Press, New York, USA, 1990; p.315-322.

Zhong DF, Sun L, Liu L, Huang HH. Microbial transformation of naproxen by Cunninghamella species. Acta Pharmacol Sini. 2003; 24: 442-447. 